\title{
The gastric disease of Napoleon Bonaparte: brief report for the bicentenary of Napoleon's death on St. Helena in 1821
}

\author{
Alessandro Lugli ${ }^{1}$ • Fatima Carneiro ${ }^{2,3}$ • Heather Dawson ${ }^{1} \cdot$ Jean-François Fléjou ${ }^{4} \cdot$ Richard Kirsch $^{5}$. \\ Rachel S. van der Post ${ }^{6} \cdot$ Michael Vieth $^{7} \cdot$ Magali Svrcek $^{8}$
}

Received: 25 January 2021 / Revised: 9 February 2021 / Accepted: 14 February 2021 / Published online: 4 March 2021

(C) The Author(s) 2021

\begin{abstract}
After the defeat at the battle of Waterloo on June 18, 1815, Napoleon Bonaparte was sent into exile to the Island of St. Helena where he died 6 years later on May 5, 1821. One day after his death, Napoleon's personal physician, Dr. Francesco Antommarchi, performed the autopsy in the presence of Napoleon's exile companions and the British medical doctors. Two hundred years later, mysteries still surround the cause of his death and different hypotheses have been postulated in the medical and historical literature. The main reasons seem to be the presence of several autopsy reports, their interpretation and perhaps the greed for thrill and mystery. Therefore, for the bicentenary of Napoleon's death, an international consortium of gastrointestinal pathologists assembled to analyse Napoleon's autopsy reports based on the level of medical evidence and to investigate if the autopsy reports really do not allow a final statement.
\end{abstract}

Keywords Napoleon · Bicentenary $\cdot$ Gastritis $\cdot$ Gastric cancer $\cdot$ Autopsy report

\section{Introduction}

Napoleon Bonaparte died on May 5, 1821, on the Atlantic Island of St. Helena. According to the autopsy reports of Napoleon's personal physician, Dr. Francesco Antommarchi (1789-1838), and the British medical doctors present at the autopsy, the pathological findings of Napoleon's stomach highly suggest a malignant gastric neoplasia. Nevertheless, even 200 years later, mysteries surround the Emperor's death. The presence of an elevated arsenic concentration in Napoleon's hair raised the hypothesis of arsenic poisoning

Alessandro Lugli

alessandro.lugli@pathology.unibe.ch

1 Institute of Pathology, University of Bern, Murtenstrasse 31, 3008 Bern, Switzerland

2 Centro Hospitalar Universitario de São João/Medical Faculty of Porto, Porto, Portugal

3 Institute of Molecular Pathology and Immunology of the University of Porto/i3S - Instituto de Investigação e Inovação em Saúde, Universidade do Porto, Porto, Portugal

4 Département de Pathologie, Cerbapath, Paris, France
[1]. Other suggested reasons for Napoleon's death, causing quite a stir, are iatrogenic drug-induced intoxication [2] and, more recently, chronic gastritis associated with anaemia due to gastrointestinal bleeding [3]. The diagnosis of gastric cancer is often challenged based on the following arguments: first, the gastric lesion is not malignant; second, if the lesion is malignant, then only at an early stage and ultimately not the cause of death; third, Napoleon's clinical history is not compatible with gastric cancer; fourth, Dr. Antommarchi's second autopsy report published in his memoirs in 1825 is a plagiarism. For the bicentenary of Napoleon's death, an international consortium
5 Pathology and Laboratory Medicine, Mount Sinai Hospital, University of Toronto, Toronto, Ontario, Canada

6 Department of Pathology, Radboud Institute for Molecular Life Sciences, Radboud University Medical Centre, Nijmegen, the Netherlands

7 Institute of Pathology, Klinikum Bayreuth Friedrich-Alexander University Erlangen-Nuremberg, Erlangen, Germany

8 Sorbonne Université, AP-HP, Hôpital Saint-Antoine, Service d'Anatomie et cytologie pathologiques, Paris, France 
of gastrointestinal pathologists reanalysed the different autopsy reports and investigated on their medical reliability with the aim to make a final conclusion on Napoleon's cause of death.

\section{The level of medical evidence of Napoleon's autopsy reports}

Napoleon's autopsy was performed on May 6, 1821, at 2 p.m. at Longwood House on the Island of St. Helena in the presence of a French and a British delegation. Napoleon's French retinue included Dr. Francesco Antommarchi, Napoleon's personal physician, Count Montholon, General Bertrand, the valet St Denis and Marchand, the butler Pierron and the priest Abbe Vignali. The British committee was represented by seven MDs, namely Archibald Arnott, Thomas Shortt, Charles Mitchell, Francis Burton, Matthew Livingstone supported by Walter Henry and George Henry Rutledge and also by Sir Thomas Reade representing Sir Hudson Lowe, Governor of the Island, Major Charles Hamilton and the Duty Officer at Longwood House William Crokat [4].

In this brief review, we therefore only investigated the sources originating from the people present at the autopsy and we further stratified the reports into three medical evidence levels (strong, moderate and weak):

Strong medical evidence The first autopsy report of Francesco Antommarchi and the British autopsy report are written by medical doctors at or just after the autopsy. They show medical knowledge and a precise description of the pathological findings. Antommarchi's first autopsy report was included in Montholon's and Marchand's memoirs [5, 6], while the official British report is preserved in the Lowe Papers at the British Library in London [7].

Moderate medical evidence Dr. Walter Henry, Assistant Surgeon, took notes during the autopsy in 1821 which were part of a letter he wrote to Sir Hudson Lowe, Governor of the Island of St. Helena, in 1823 [7]. Despite the similarity of the pathological findings described in the reports of 1821, the delay of 2 years may imply some potential impreciseness.

Weak medical evidence General Henri Gatien Bertrand was Napoleon's exile companion and his diary was published in Paris in the twentieth century [4]. Bertrand is not a medical doctor and the short description of the pathological findings does not add any further information. Louis-Etienne SaintDenis was Napoleon's valet. Despite his presence at the autopsy, he did not take any notes, but published his memoirs several years later including a short description of Napoleon's stomach at the autopsy: "There was a perforation in the stomach and around this perforation many little holes as made by lead shots of a pistol" [8]. Compared to the autopsy reports of
1821, the description is incomplete and from a medical point of view not at a professional level.

Antommarchi published in 1825 "Les Derniers Moments de Napoleon", including a second autopsy report with additional findings not originally described [9]. In 2006, this report was found to have striking similarities with an article published in the French medical journal Archives Générales de Médecine in 1823 and since then should be considered a plagiarism and was therefore excluded from the present review [9].

A short overview of Napoleon's different autopsy reports is summarized in Table 1.

\section{Interpretation of the autopsy reports of 1821 signed by Dr. Antommarchi and the British doctors}

Some summarized excerpts with focus on the pathological findings in Napoleon's stomach are presented in Table 2 [6, 7]. Their interpretation allows the following five statements:

1. The cardiac extremity for a small space near the termination of the oesophagus was the only part appearing in a healthy state.

2. The stomach was nearly filled with a large quantity of black liquid of disagreeable odour resembling coffee grounds.

3. The internal surface of the stomach to nearly its whole extent, extending from the cardiac orifice to about an inch from the pylorus, was a mass of cancerous disease/ scirrhous portions advancing to cancer/extensive cancerous ulcer.

4. The ulcerated surface of the stomach was considerably swollen and indurated.

5. Presence of a perforated ulcer (diameter: $6-7 \mathrm{~mm}$ ) which was located one inch from the pylorus. The ulcer was covered by strong adhesions located between the stomach and the liver.

\section{Clinico-pathological aspects of Napoleon's final disease}

For medical doctors specialized in gastrointestinal diseases, these statements are very suggestive for the diagnosis of an advanced malignant gastric neoplasia (gastric carcinoma and/ or gastric lymphoma) associated with a covered perforated ulcer and upper gastrointestinal bleeding.

Nevertheless, since Napoleon's autopsy, the diagnosis of gastric cancer was questioned several times in the medicohistorical literature. In 1961, an elevated arsenic concentration in Napoleon's hair taken after his death suggested arsenic 
Table 1 Overview of Napoleon's different autopsy reports

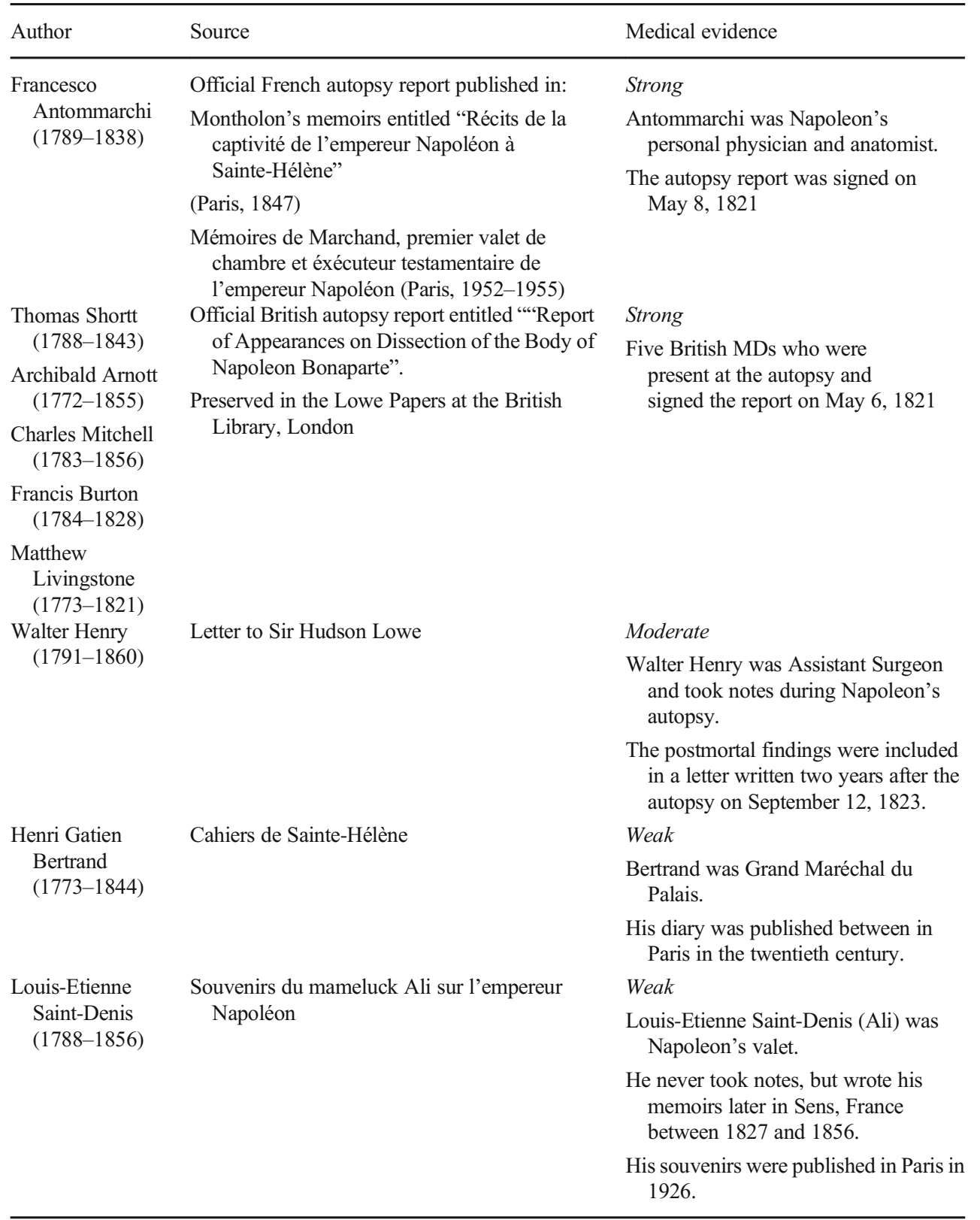

poisoning [1]. This hypothesis was finally dismissed by a study published in 2008 showing an elevated arsenic content in the hair of Napoleon during his childhood as well as in the hairs of Napoleon's son and Joséphine [10]. This study along with others excluded an arsenic poisoning with criminal intent [3, 7, 11, 12]. In 2012, a medico-historical book challenges gastric cancer again and a chronic gastritis associated with gastrointestinal bleeding and anaemia was suggested as Napoleon's cause of death instead [3]. The following clinico-pathological aspects clearly show why this hypothesis stays on an extremely shaky ground:

Based on the WHO classification of digestive tumours (5th edition 2019), common symptoms of gastric cancer, especially in advanced stages, include asthenia, indigestion, vomiting, weight loss, dysphagia, early satisfaction of appetite and anaemia [13]. According to historical, sources Napoleon showed quite several of these symptoms, especially in the last few months of his life [4-6, 8, 14]. Additionally, the anaemia may be simply tumour-related.

On May 3, 1821, 2 days before his death, Napoleon was given Calomel (mercurous chloride) by his doctors leading to the hypothesis of an iatrogenic drug-induced cause of death. Napoleon was already tachycardic before May 3 [4] which supports along with the postmortal findings his advanced malignant gastric neoplasia being the cause for the gastric bleeding and Calomel just a trigger. Napoleon's health status was decreasing since October 1820 which is in line with cancer progression and makes an "unnatural" component [12] unlikely. 
Table 2 Summarized extracts from the first autopsy report of Francesco Antommarchi in comparison to the British autopsy report with focus on the pathological findings in Napoleon's stomach [5-7]

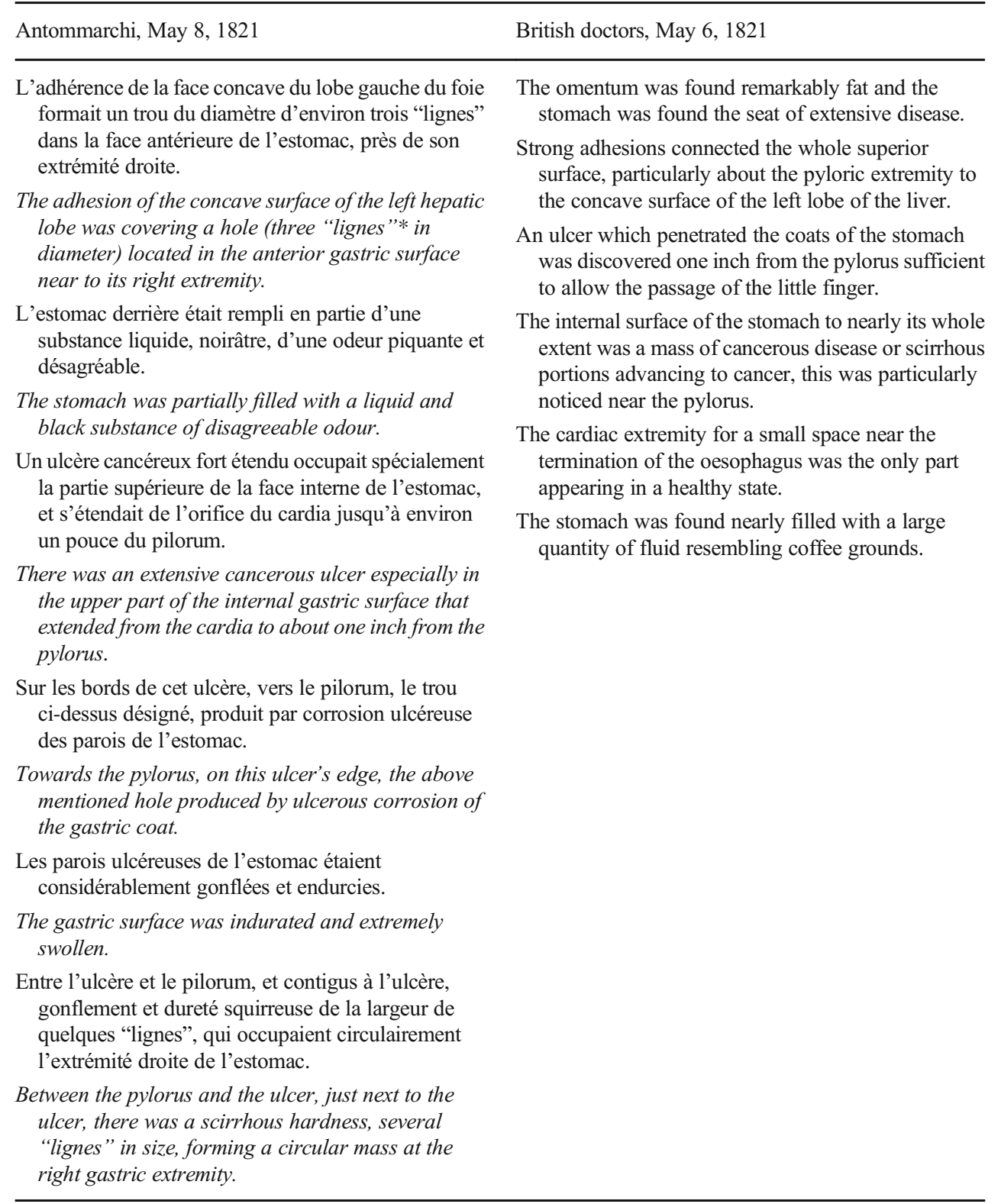

The summary of Dr. Antommarchi's autopsy report is exceptionally presented in French to avoid any misunderstandings and bias due to translation. For completeness, the English translation is also available at the bottom of each paragraph $(* 1$ ligne $=$ approximately $2.256 \mathrm{~mm})$
The macroscopic description in the two original autopsy reports does not favour chronic gastritis at all. In previous publications, the macroscopy of Napoleon's stomach was compared with several pictures of non-treated gastritis and gastric cancer [11] [14]. None of the gastritis pictures were in the least comparable to the description in Napoleon's autopsy reports in contrast to the macroscopic aspect of gastric cancer Borrmann subtype III. The description of Saint-Denis in his memoirs stating "There was a perforation in the stomach and around this perforation many little holes as made by lead shots of a pistol" [8], may be well-intentioned, but clearly incomplete and not medically sound.
There is a strong evidence for an association between tumour size and tumour stage in gastric cancer [11, 14]. Indeed, Napoleon's gastric lesion is associated with an advanced gastric cancer even according to the autopsy report of 1821 by Antommarchi and the one signed by the British doctors, respectively $[11,14]$. Having excluded Antommarchi's autopsy report of 1825 , the lack of evident metastases in the autopsy reports from 1821 is still not surprising as often loco-regional lymph node metastases are only detected microscopically. Since histological confirmation of the cancer is not available, we cannot be sure of the histological subtype. However, the metastatic pattern of both intestinal and diffuse type gastric cancer is often 


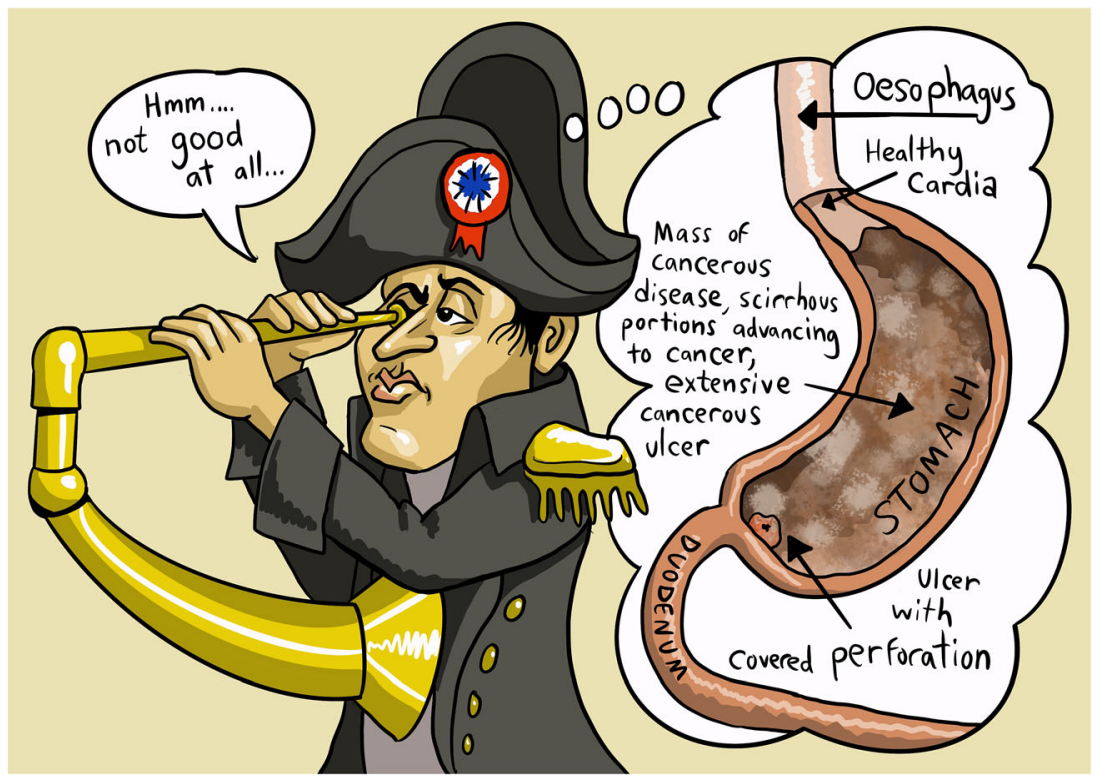

Fig. 1 Morphologic visualization of Napoleon's gastric lesion based on the autopsy reports of Francesco Antommarchi (May 8, 1821) and the British doctors, Thomas Shortt, Arch Arnott, Charles Mitchell, Francis

associated with (distant) lymph nodes and peritoneal metastases (with or without ascites) which may be easily missed during the autopsy. Nevertheless, according to Siddharta Mukherjee's book "The emperor of all maladies. A biography of cancer", there is strong evidence that cancer was a known entity before 1821 [15].

The co-existence of malignant gastric neoplasia (carcinoma and/or lymphoma) and gastric ulcer with perforation may suggests a Helicobacter pylori gastritis associated carcinogenesis [13].

\section{Conclusion}

The autopsy reports signed just after Napoleon's autopsy on May 6 and May 8 by the British doctors and Francesco Antommarchi show strong medical evidence and allow a final diagnosis: advanced malignant gastric neoplasia associated with upper gastrointestinal bleeding as cause of death. Napoleon lost his final battle against an enemy who even in our days is unfortunately still strong: cancer, emperor of all maladies.

Acknowledgements We would like to thank David Levine, Liebefeld, Bern, Switzerland, for the creation of Fig. 1.

Author contributions Alessandro Lugli: study design, editing manuscript, discussion and interpretation of Napoleon's autopsy reports, editing tables and figure

Fatima Carneiro: editing manuscript, discussion and interpretation of Napoleon's autopsy reports

Heather Dawson: editing manuscript and tables, discussion and interpretation of Napoleon's autopsy reports
Burton and Matthew Livingstone (May 6, 1821). Created by David Levine based on an idea of Alessandro Lugli

Jean-François Fléjou: editing manuscript, discussion and interpretation of Napoleon's autopsy reports

Richard Kirsch: editing manuscript, discussion and interpretation of Napoleon's autopsy reports

Rachel S. van der Post: editing manuscript, discussion and interpretation of Napoleon's autopsy reports

Michael Vieth: editing manuscript, discussion and interpretation of Napoleon's autopsy reports

Magali Svrcek: editing manuscript, discussion and interpretation of Napoleon's autopsy reports, editing tables and figure

Funding Open Access funding provided by Universität Bern.

\section{Declarations}

Ethics approval The present manuscript is a retrospective medicohistorical brief commentary (review) based on already existing data in the medico-historical literature. This brief commentary does not involve humans and/or animals and does not have implications for general welfare or public health. Therefore, no approval by an Internal Review Board/Ethics committee was required.

Conflict of interest The authors declare no competing interests.

Open Access This article is licensed under a Creative Commons Attribution 4.0 International License, which permits use, sharing, adaptation, distribution and reproduction in any medium or format, as long as you give appropriate credit to the original author(s) and the source, provide a link to the Creative Commons licence, and indicate if changes were made. The images or other third party material in this article are included in the article's Creative Commons licence, unless indicated otherwise in a credit line to the material. If material is not included in the article's Creative Commons licence and your intended use is not permitted by statutory regulation or exceeds the permitted use, you will need to obtain permission directly from the copyright holder. To view a copy of this licence, visit http://creativecommons.org/licenses/by/4.0/. 


\section{References}

1. Forshufvud S, Smith H, Wassen A (1961) Arsenic content of Napoleon I's hair probably taken immediately after his death. Nature 192:103-105

2. Mari F, Bertol E, Fineschi V, Karch SB (2004) Channelling the Emperor: what really killed Napoleon? J R Soc Med 97(8):397-399

3. Goldcher A (2012) Napoléon Ier. L'ultime autopsie. SPM Editions, Paris

4. Bertrand H (1951) Cahiers de Sainte-Hélène. Editions Albin Michel, Paris

5. Marchand L (2003) Mémoires de Marchand. Premier valet de chambre et éxécuteur testamentaire de l'empereur Napoléon. Publiés par Jean Bourguignon et le commandant Henri Lachouque. Tallandier Editions, Paris

6. Montholon MLG (1847) Récits de la captivité de l'empereur Napoléon a Sainte-Hélène. Paulin, Librairie-Editeur, Paris

7. Hindmarsh JT, Corso PE (2007) The death of Napoleon: the last campaign. Xlibris, Bloomington, Indiana, USA

8. Saint-Denis LE (1926) Souvenirs du Mameluck Ali sur l'empereur Napoléon. Payot, Paris

9. Jeandel R, Bastien J (2006) Antonmarchi, last physician of Napoleon: requiem for a forger. Autopsy report published in 1825 is a plagiarism! Med Sci (Paris) 22(4):434-436

10. Clemenza C, Fiorini E, Guerra L, Herborg C, Labra M, Orvini E, Piazzoli A, Previtali E, Puggioni F, Santagostino A (2008) Misure con attivazione neutronica sulla presenza di arsenico nei capelli di
Napoleone Bonaparte e di suoi famigliari. Il nuovo saggiatore 24(12):19-30

11. Dawson H, Novotny A, Becker K, Reim D, Langer R, Gullo I, Svrcek M, Niess JH, Tutuian R, Truninger K, Diamantis I, Blank A, Zlobec I, Riddell RH, Carneiro F, Flejou JF, Genta RM, Lugli A (2016) Macroscopy predicts tumor progression in gastric cancer: A retrospective patho-historical analysis based on Napoleon Bonaparte's autopsy report. Dig Liver Dis 48(11):1378-1385. https://doi.org/10.1016/j.dld.2016.07.013

12. Marchetti D, Cittadini F, De Giovanni N (2020) Did poisoning play a role in Napoleon's death? A systematic review. Clin Toxicol (Phila):1-15. https://doi.org/10.1080/15563650.2020.1843658

13. WHO Classification of Tumours Editorial Board (2019) Digestive System Tumours, 5th edn. IARC, Lyon, France

14. Lugli A, Clemenza M, Corso PE, di Costanzo J, Dirnhofer R, Fiorini E, Herborg C, Hindmarsh JT, Orvini E, Piazzoli A, Previtali E, Santagostino A, Sonnenberg A, Genta RM (2011) The medical mystery of Napoleon Bonaparte: an interdisciplinary expose. Adv Anat Pathol 18(2):152-158. https://doi.org/10.1097/ PAP.0b013e31820ca329

15. Mukherjee SC (2011) The emperor of all maladies. A Biography of cancer. Fourth Estate. An imprint of HarperCollinsPublishers, London

Publisher's note Springer Nature remains neutral with regard to jurisdictional claims in published maps and institutional affiliations. 